\title{
Potential isotopic and chemical markers for characterising organic fruits
}

${ }^{1}$ Camin F.*, ${ }^{1}$ Perini M, ${ }^{1}$ Bontempo L., ${ }^{2}$ Fabroni S., ${ }^{3}$ Faedi W., ${ }^{3}$ Magnani S., ${ }^{3}$ Baruzzi G., ${ }^{3}$ Bonoli M., ${ }^{4}$ Tabilio MR, ${ }^{4}$ Musmeci S, ${ }^{5}$ Rossmann A., ${ }^{6}$ Kelly S.D., ${ }^{2}$ Rapisarda P.

${ }^{1}$ IASMA - Edmund Mach Foundation, via Mach 1, 38010 San Michele all'Adige (TN) Italy

${ }^{2}$ CRA-ACM, Corso Savoia 190, 95024 Acireale (CT) Italy

${ }^{3}$ CRA-FRF, Via la Canapona 1 bis, 47021 Magliano, Forlì, Italy

${ }^{4}$ CRA-FRU, via Fioranello 52, 00134 Roma, Italy

${ }^{5}$ Isolab GmbH, Woelkestr. 9/1, D-85301 Schweitenkirchen, Germany

${ }^{6}$ School of Environmental Sciences, University of East Anglia, Norwich, NR4 7TJ, UK

* fax: +390461 615200; e-mail: federica.camin@iasma.it

Keywords: organic/conventional; orange; peach; strawberry; H, C, O, N, S stable isotope ratios; quality parameters

\begin{abstract}
Several isotopic $\left({ }^{13} \mathrm{C} /{ }^{12} \mathrm{C},{ }^{15} \mathrm{~N} /{ }^{14} \mathrm{~N},{ }^{18} \mathrm{O} /{ }^{16} \mathrm{O},{ }^{2} \mathrm{H} /{ }^{1} \mathrm{H},{ }^{34} \mathrm{~S} /{ }^{32} \mathrm{~S}\right)$ and chemical-physical parameters ( $\mathrm{pH}$, fruit weight, juice yield, titratable acidity, total soluble solids, skin resistance, flesh firmness, colorimetric characteristics, weight loss after harvesting, antioxidant activity, earliness index, total nitrogen, ascorbic acid, synephrine, anthocyanins and polyphenols, citric acid, malic acid, sucrose, glucose and fructose content) were investigated as potential markers of organically cultivated oranges, clementines, strawberries and peaches produced in Italy between 2006 and 2008, in experimental fields and in certified farms. The ratio ${ }^{15} \mathrm{~N} /{ }^{14} \mathrm{~N}$, ascorbic acid and total soluble solids were shown to be the most significant variables for distinguishing between organically and conventionally cultivated fruits. It was not possible to define general threshold limits typical of organic fruits because these parameters are influenced also by fruit specie, cultivar, year and site of production. Combining isotopic and chemical markers a good discrimination between organic and conventional fruits of different species was achieved.
\end{abstract}

\section{Introduction}

The application of nitrogen stable isotope ratio ${ }^{15} \mathrm{~N} /{ }^{14} \mathrm{~N}$ (expressed as $\delta^{15} \mathrm{~N}$ ) analysis to discriminate organic from conventional cultivation has been discussed in detail previously (Bateman, Kelly \& Woolfe, 2007; Rogers, 2008). It is based on the fact that synthetic nitrogen fertilisers, commonly used in conventional agriculture and not permitted in organic agriculture, have $\delta^{15} \mathrm{~N}$ values significantly lower (from $-6 \%$ o to $6 \%$ ) than the manures and fertilisers (from $1 \%$ to $37 \%$ ) permitted in organic agriculture (Bateman \& Kelly, 2007). Because for most terrestrial plants (except for $\mathrm{N}_{2}$ fixator plants) the applied fertiliser is one of the main sources of nitrogen, organic crops should exhibit $\delta^{15} \mathrm{~N}$ values significantly higher than their conventional counterparts. This was in fact observed in several recent studies concerning principally vegetable crops produced mainly under controlled conditions (Nakano, Uehara, \& Yamauchi, 2003; Choi, Lee, Ro, Kim \& Yoo, 2002; Choi, Ro, \& Hobbie, 2003; Bateman, Kelly \& Jickells, 2005; Georgi, Voerkelius, Rossmann, Grassmann \& Schnitzler, 2005; Schmidt et al, 2005; Rapisarda, Calabretta, Romano \& Intrigliolo, 2005; Bateman, Kelly \& Woolfe, 2007; Camin et al., 2007; Flores, Fenoll \& Hellín, 2007; Kelly \& Bateman, 2009; Rapisarda, Camin, Fabroni, Perini, Torrisi \& Intrigliolo, 2010). In general it can be concluded that the $\delta^{15} \mathrm{~N}$ analysis can be a useful discriminant tool for glasshouse grown crops and for other crops requiring intensive horticulture, but not for all cultivation typologies especially in soil grown crops with a long growth cycle. It was also suggested to combine this analysis with other analytical approaches (other stable isotope ratios or secondary metabolic profiling) to improve the discrimination capability. It is of note that most of the publications concerned crop production, whereas only two papers investigated fruits. 
In this work we present the measurement of several isotopic and chemical-physical parameters as possible markers of organic oranges, clementine, strawberries and peaches cultivated in Italy between 2006 and 2008 in both experimental fields and in certified organic and conventional farms. The organic fruits were grown in accordance with Council Regulation (EC) No. $834 / 2007$ of 28 June 2007 on organic production and labelling of organic products and repealing Regulation (EEC) No. 2092/91. Along with $\delta^{15} \mathrm{~N}$ of fruit 'pulp', other isotopic ratios $\left({ }^{13} \mathrm{C} /{ }^{12} \mathrm{C}\right.$, ${ }^{2} \mathrm{H} /{ }^{1} \mathrm{H},{ }^{34} \mathrm{~S} /{ }^{32} \mathrm{~S}$ of 'pulp' and ${ }^{18} \mathrm{O} /{ }^{16} \mathrm{O}$ of fruit juice water) as well as some other chemical and physical characteristics $(\mathrm{pH}$, fruit weight, juice yield, titratable acidity, total soluble solids, skin resistance, flesh firmness, colorimetric characteristics, weight loss after harvesting, antioxidant activity, earliness index, total nitrogen, ascorbic acid, synephrine, anthocyanins and polyphenols, citric acid, malic acid, sucrose, glucose and fructose content) were considered. Some of these parameters have been discussed in the literature as demonstrating the potential to discriminate between foods produced under organic and conventional regimes. Higher phenolic compounds, ascorbic acid and dry matter content was found in organic fruits or vegetables whereas higher nitrogen-alkaloids (such as synephrine, Rapisarda et al., 2005) and nitrate content were found in conventional products (Lairon, 2009), despite the fact that other studies have concluded that no significant differences between the two agricultural regimes have been observed (Dangour, Dodhia, Hayter, Allen, Lock \& Uauy, 2009). The observed differences may be explained by the fact that in the case of nitrogen limitation, which more often occurs in organic production regimes, plants would enhance synthesis of 'nitrogen-poor' compounds. Another explanation at least to interpret increases in antioxidants in organic samples is that the increased pathogen pressure leads to a buildup of endogenous plant defence compounds (Brandt \& Molgaard, 2001; Carbonaro, Mattera, Nicoli, Bergamo \& Cappelloni, 2002). Significantly lower $\delta^{13} \mathrm{C}$ was moreover observed in organic onions and cabbages (Georgi et al., 2005), due to the higher microbiological activity in the soil of the organic regime resulting in respiratory $\mathrm{CO}_{2}$ with lower $\delta^{13} \mathrm{C}$. Another explanation could be that in conditions of higher $\mathrm{N}$ availability as in conventional crops, rate of photosynthesis may increase, followed by lower discrimination of the enzyme RuBisCo against ${ }^{13} \mathrm{CO}_{2}$ (Hogberg, Johannosson, Hog, Nasholm \& Hallgren, 1995). Georgi and co-authors (Georgi et al., 2005) also hypothesised different ${ }^{18} \mathrm{O}$ and ${ }^{2} \mathrm{H}$ content in organic and conventional productions, as a consequence of the different density and size of plants that characterise the two agricultural regimes. These in fact can influence factors such as evapotranspiration and water uptake of plants, with a significant effect on $\delta^{18} \mathrm{O}$ and $\delta^{2} \mathrm{H}$ of plant water and material. Moreover we suppose that organic product fertilised with marine-derived fertilisers, should have higher $\delta^{34} \mathrm{~S}$ values than sulphate fertilisers derived from sulphuric acid, because marine sulphate possesses a higher ${ }^{34} \mathrm{~S}$ content (Otsuchi, Sanriku, Carvalho, Hayashizaki \& Ogawa, 2008; Schmidt, Quilter, Bahar, Moloney, Scrimgeour \& Begley, 2005). However, to our knowledge no evidence of these latter differences are reported in the literature.

The aim of the present study was to assess if the combination of several analytical approaches allow to discriminate between organic and conventional fruits. This is an important issue because despite the increasing higher value of the organic market, traceability of organic products is solely based on adherence to specific guidelines (EC Regulation No. 834/07). The availability of markers allowing to determinate the agricultural regime of commercial products and therefore to verify labelling claims can greatly help fraud prevention.

\section{Materials and methods}

In Table 1 the number of samples grouped by year and area of production, cultivar and agricultural systems is shown.

Oranges and clementines were produced from 2006 to 2008 in several conventional and certified organic farms in Sicily and Calabria respectively, managed for at least 3 years according to conventional and organic agricultural practices and selected in order to have homogeneity of age and rootstock of the orchards. Conventional farming systems were based on the Best Agricultural Practices of the region, according to the Integrated Pest Management (IPM) approach. Nutrient inputs were made with granular synthetic fertilizers both in simple (N, P, K) and in complex (NPK) 

derived from organic fertilizers consisting of composted plant and animal residues, while $\mathrm{P}$ and $\mathrm{K}$ inputs were derived from soft ground rock phosphate and a potassium sulfate salt (containing magnesium), respectively. For each sample, 30-40 oranges and 40-60 clementines were taken oranges, 'Navelina' with yellow flesh and 'Tarocco' with red flesh, and the cultivar 'Comune' for clementines.

Organic and conventional peaches were produced from 2006 to 2008 in 2 adjacent orchards of the experimental field of the CRA-FRU (Rome), that were subjected to the same irrigation, thinning and pruning practices and to the same soil management. Before the field based experiments were started, $50 \%$ of Lolium perenne, $40 \%$ of Festuca rubra and $10 \%$ of Poa pratensin were cultivated. Organic orchards received 3 different quantities of certified organic fertiliser: one with a contribution in $\mathrm{N}, \mathrm{K}$ and $\mathrm{P}$ identical to the conventional orchard $(112 \mathrm{~kg} / \mathrm{ha}$ of $\mathrm{N}, 60 \mathrm{~kg} / \mathrm{ha}$ of $\mathrm{P}, 85 \mathrm{~kg} / \mathrm{ha}$ of K), and the other two with a lower contribution $(78 \mathrm{~kg} / \mathrm{ha}$ of $\mathrm{N}, 51 \mathrm{~kg} / \mathrm{ha}$ of $\mathrm{P}, 56$ $\mathrm{kg} / \mathrm{ha}$ of $\mathrm{K}$ and $44 \mathrm{~kg} / \mathrm{ha}$ of N, $41 \mathrm{~kg} / \mathrm{ha}$ of P, $27 \mathrm{~kg} / \mathrm{ha}$ of $\mathrm{K}$. Each sample was made of 5 fruits from the trees of one row, considering: 4 cases ( 1 conventional and 3 organic); 2 cultivars: 'Spring lady' with yellow pulp and harvest time at the first two weeks of June, and 'White Queen' with white pulp and harvest time in the first two weeks of August; from 1 to 3 rows of trees; 2 sampling times in a period of two weeks.

Strawberries were produced in an experimental farm of CRA FRF located at Cesena (Emilia Romagna) and in conventional and certified organic farms in Verona (Veneto) and in Metaponto, (Basilicata). The experimental strawberries of 4 different cultivars from Cesena were grown from 2006 to 2008 in 2 adjacent fields with similar pedological characteristics, adopting a cultivation system at open field and the organic or traditional practices indicated in the production rules of the region Emilia Romagna. Strawberry samples from Verona and Metaponto were cultivated in 2007 and 2008 in conventional and certified organic farms, considering one farm for each site and for each agricultural system. Fruits of 3 different cultivars were grown in protected crop culture. The following applications of nitrogen were applied to the conventional strawberries: $125 \mathrm{Kg} / \mathrm{ha}$ of organic nitrogen in Cesena, $150 \mathrm{Kg} / \mathrm{ha}$ in Verona, $210 \mathrm{Kg} / \mathrm{ha}$ in Metaponto and, after planting, 12 $\mathrm{Kg} / \mathrm{ha}$ of mineral nitrogen in Cesena, $120 \mathrm{Kg} / \mathrm{ha}$ in Verona and $100 \mathrm{Kg} / \mathrm{ha}$ in Metaponto. For organic fruits the soil was managed with a quadrennial cycle crop rotation using Brassica Juncea in Cesena and wheat in Verona; in Metaponto soil was managed with a crop rotation composed of green manure based on leguminous plants. Each sample was composed of approximately 20 fruits taken from one plant.

\section{Stable isotope ratio analysis}

All of the samples were subjected to the analysis of ${ }^{15} \mathrm{~N} /{ }^{14} \mathrm{~N}$ and ${ }^{13} \mathrm{C} /{ }^{12} \mathrm{C}$ in the fruit pulp and of ${ }^{18} \mathrm{O} /{ }^{16} \mathrm{O}$ in the fruit juice water. ${ }^{2} \mathrm{H} /{ }^{1} \mathrm{H}$ and ${ }^{34} \mathrm{~S} /{ }^{32} \mathrm{~S}$ of pulp were measured in a subset of samples. Pulp was extracted from fruits following the procedure of the ENV 13070 method. In the case of strawberries a preliminary filtration was made in order to eliminate the seeds. ${ }^{13} \mathrm{C} /{ }^{12} \mathrm{C}$ and ${ }^{15} \mathrm{~N} /{ }^{14} \mathrm{~N}$ were measured using an Isotope Ratio Mass Spectrometer (Delta plus XP ThermoFinnigan, Bremen, Germany) following total combustion in an Elemental Analyser (EA Flash 1112 ThermoFinnigan) whereas, ${ }^{2} \mathrm{H} /{ }^{1} \mathrm{H}$ was measured following pyrolysis in a High Temperature Conversion/Elemental Analyser (TC/EA ThermoFinnigan) of the sample. ${ }^{34} \mathrm{~S} /{ }^{32} \mathrm{~S}$ was measured with a Vario EL III elemental analyser (Elementar Analysensysteme GmbH, Hanau/Germany) coupled to a GVI 2003 or a GVI Isoprime IRMS (GV Instruments Ltd., Manchester, UK) for the simultaneous determination of $\mathrm{C}, \mathrm{N}$ and $\mathrm{S}$ isotopic ratios. The operational conditions have been reported in previous publications (Camin, Perini, Colombari, Bontempo \& Versini, 2008; Perini, Camin, Bontempo, Rossmann \& Piasentier, 2009). ${ }^{18} \mathrm{O} /{ }^{16} \mathrm{O}$ of juice water was analysed in $\mathrm{CO}_{2}$ according to the water equilibration method described in the ENV 12141 method (Isoprep $18 \mathrm{VG}$ ISOGAS - IRMS SIRA II VG ISOGAS). The values were expressed in $\delta \%$ (Camin et al., 2010) against international standards (Vienna- Pee Dee Belemnite for $\delta^{13} \mathrm{C}$, Air for $\delta^{15} \mathrm{~N}$, Vienna - 
Standard Mean Ocean Water for $\delta^{18} \mathrm{O}$ and $\delta^{2} \mathrm{H}$, and V-CDT for $\left.\delta^{34} \mathrm{~S}\right)$. The isotopic values were calculated against working in-house standards (commercial casein and tap water), calibrated against international reference materials: L-glutamic acid USGS 40 (IAEA-International Atomic Energy Agency, Vienna, Austria), mineral oil NBS-22 (IAEA) and sugar IAEA-CH-6 (IAEA) for ${ }^{13} \mathrm{C} /{ }^{12} \mathrm{C}$ and L-glutamic acid USGS 40 for ${ }^{15} \mathrm{~N} /{ }^{14} \mathrm{~N}$ measurement; NBS-22 for ${ }^{2} \mathrm{H} /{ }^{1} \mathrm{H}$; V-SMOW for ${ }^{18} \mathrm{O} /{ }^{16} \mathrm{O}$ of water. The ${ }^{34} \mathrm{~S} /{ }^{32} \mathrm{~S}$ measurements were calibrated against a bovine casein reference material with an assigned value $\left(\delta^{34} \mathrm{~S}=4.4 \%\right.$ ) and IAEA S-1 silver sulphide standard. The ${ }^{2} \mathrm{H} /{ }^{1} \mathrm{H}$ values were corrected against the same casein reference material with an assigned value of $\delta^{2} \mathrm{H}$, according to the "comparative equilibration technique" (Wassenaar \& Hobson, 2003)

The uncertainty $(2 \sigma)$ of measurements was $\pm 0.3 \%$ for the $\delta^{13} \mathrm{C}$ and $\delta^{15} \mathrm{~N}$ of pulp, $\pm 0.2 \%$ for $\delta^{18} \mathrm{O}$ in juice water, $\pm 3 \%$ for the $\delta^{2} \mathrm{H}$ and $\pm 0.6 \%$ for $\delta^{34} \mathrm{~S}$.

\section{Chemical parameters}

\section{Citrus fruit (oranges and clementines)}

Physicochemical parameters (fruit weight, juice yield, total soluble solids, titratable acidity and $\mathrm{pH}$ ) were measured using standard methods (Kimball, 1991). The colour of the peel and pulp was evaluated as CIE L*a*b* values using a Minolta CR-300 chroma meter (Minolta Camera C., Osaka, Giappone). Ascorbic acid content was measured using a HPLC system (Waters, Milford, CA) (Rapisarda \& Intelisano, 1996). Briefly, $10 \mathrm{~mL}$ of juice was diluted to $100 \mathrm{~mL}$ with a solution of $3 \%$ metaphosphoric acid. The sample was centrifuged at $5000 \mathrm{rpm}$ for $20 \mathrm{~min}$ and filtered through a $0.45 \mu \mathrm{m}$ syringe filter prior to HPLC injection. The column was a $250 \mathrm{~mm}$ x $4.6 \mathrm{~mm}$ i.d., $5 \mu \mathrm{m}$, Hypersil ODS (Phenomenex, Torrance CA) and the solvent system was isochratic and composed of $0.02 \mathrm{M}$ phosphoric acid at a flow rate of $1.0 \mathrm{~mL} / \mathrm{min}$. Total nitrogen in the juice was determined according the Kjeldahl method and synephrine content determined using the HPLC method described by Rapisarda et al. (2005).

\section{Peaches}

Total anthocyanin and polyphenol content, as well as the anti-oxidant activity, were measured in both peel and pulp. $5 \mathrm{~g}$ of peel and pulp were suspended in $25 \mathrm{~mL}$ of a water solution containing $70 \% \mathrm{v} / \mathrm{v}$ methanol acidified with $1 \% \mathrm{v} / \mathrm{v}$ of $37 \% \mathrm{v} / \mathrm{v}$ hydrochloric acid. After 2 hours in a boiling water bath (Bain-Marie) the solution was centrifuged at $3500 \mathrm{rpm}$ for 15 minutes and the pellet was extracted again with $20 \mathrm{~mL}$ of acidified solution described above. The two supernatant fractions were combined and diluted to $50 \mathrm{~mL}$ with deionised water.

Total anthocyanins were determined using a spectrophotometer (UV visible spectrophotometer Evolution 300 Thermo Scientific) by measuring the absorbance at $520 \mathrm{~nm}$, whereas polyphenol content was determined according to the Folin-Ciocalteau method (Swain \& Hills 1959). The results were expressed as $\mathrm{mg}$ of cyanidin chloride/100 $\mathrm{g}$ of fresh fruit for anthocyanins and as $\mathrm{mg}$ of gallic acid $/ 100 \mathrm{~g}$ of fresh fruit polyphenols. The antioxidant activity was tested using the DPPH radical (2.2-diphenyl-1-picrylidrazyl) according to the procedure described in Brand-Williams, Cuvelier \& Berset (1995) and it was expressed as mg of trolox/100 g of fresh fruit.

\section{$\underline{\text { Strawberries }}$}

In 20 fruits of each sample, the following parameters were evaluated:

- $\quad$ skin resistance (SR), compressing the fruits between two plates till a deformation of $2 \mathrm{~mm}$ occurred in a manual Durometer DFE (Chatillon Ametek Inc., LLOYD instrument, U.K.)

- $\quad$ flesh firmness (FF): Ametek digital penetrometer with a $6 \mathrm{~mm}$ diameter star-shaped plug

- $\quad$ total soluble solids (TSS): ${ }^{\circ}$ Brix, digital Refractometer Atago, PR-32 Alpha (LaboandCo, Torino, Italy)

- $\quad$ titratable acidity (TA): 702 SM Titrino titolator, Metrhom Swiss; titolation with NaOH 0.1 $\mathrm{N}, \mathrm{pH} 7.00)$ 
- $\quad$ skin colour with a Minolta Chroma Meter CR-200 reflectance colorimeter (8 $\mathrm{mm}$ window,

\section{Results and discussion}

In Tables 2, 3 and 4 the level of significance of the experimental factors influencing the isotopic and chemical data - agricultural regime (organic/conventional), cultivar, year and site of production and factor interactions when reliable (ANOVA results) -, as well as the mean and standard deviation of the data grouped according to agricultural regime, cultivar or production site and production year are summarised for citrus, peaches and strawberries, respectively. Strawberry samples were grouped according to their production site instead of cultivar, to have a lower number of more numerous groups.

By applying Kolmogorov-Smirnov test, the data were shown to be normally distributed within the respective groups. Because variance was not always homogeneous among groups, both parametric (ANOVA and HSD, Honestly Significantly Different, for unequal N Tukey's) and non-parametric (Kruskall-Wallis and multiple bilateral comparison) tests were applied in order to verify the significance of the analytical parameters as markers of the organic production and the influence of other variables (cultivar, year and site of production) in the data. Because the results of the two tests were generally in accordance, only the results of ANOVA and of HDS for unequal N Tukey's test's (Tables 2, 3, 4) are reported.

\section{Stable isotope ratios of $H, C, N, O$ and $S$}

$\delta^{15} \mathrm{~N}$ was shown to be a highly significant parameter for distinguishing organic and conventional fruits $(p<0.001$ for oranges, peaches and strawberries) (Tables 2-4). This is due to the different fertilisation practices of the two agricultural systems. Synthetic mineral fertilisers derived from air in the Haber process (with lower $\delta^{15} \mathrm{~N}$ ), are not permitted in the organic production (EC Regulation No. 834/07). Inspection of the Tukey's test results (Tables 2-4) shows that the organic oranges and peaches of both the cultivars and of all the years considered as well as strawberries from Verona have $\delta^{15} \mathrm{~N}$ values of the pulp significantly higher $(\mathrm{p}<0.05)$ than the conventional cultivated fruits. For strawberries from Metaponto 2007 and Cesena and for clementine, $\delta^{15} \mathrm{~N}$ values were similar between organic and conventional fruits, because organic fertiliser was used in the conventional agricultural regime. The significantly lower $\delta^{15} \mathrm{~N}$ values of organic strawberries from Metaponto 2008 can be explained by the fact that the soil was managed with crop rotation and derived from green manure based on leguminous ( $\mathrm{N}$-fixing) plants, that use air nitrogen with $\delta^{15} \mathrm{~N}$ close to $0 \%$. Beside the production system, $\delta^{15} \mathrm{~N}$ of peaches was significantly $(\mathrm{p}<0.001)$ affected by cultivar and year, whereas that of strawberry by cultivar, site of origin and by the interaction of site with production system. For oranges, only the production system was highly significant (Table 2). 
$259 \delta^{13} \mathrm{C}$ was found significant to distinguish organic and conventional peaches $(\mathrm{p}<0.01)$ and 260 strawberries $(\mathrm{p}<0.05)$ (Table 3,4$)$, with the hypothesized significantly lower $\delta^{13} \mathrm{C}$ values for organic 261 fruits found only in White Queen peaches 2007 and $2008(\mathrm{p}<0.05)$. The lower values of peaches cannot be justified on this basis of the different microclimatic or soil conditions of the area (O'Leary, 1995), because climate, as well as soil, soil treatment, nitrogen availability of fertiliser at least for one organic thesis, irrigation and plant thinning out (see Material and Methods section) were exactly the same for the two crops. The lower values can be explained on the basis of the higher microbiological activity of the organic cultivation, as described previously in the literature (Georgi et al., 2005). However, factors such as cultivar or site of production resulted in more statistically significant differences of $\delta^{13} \mathrm{C}$ values than the production system.

The $\delta^{2} \mathrm{H}$ of pulp measured in a subset of samples, was shown to be highly significant $(\mathrm{p}<0.001)$ for differentiating the production origin of strawberries whereas $\delta^{18} \mathrm{O}$ of juice water was found to be significant for peaches $(\mathrm{p}<0.05)$. Considering different years, cultivar or site (Tables $2-4)$, we found pulp $\delta^{2} \mathrm{H}$ to be significantly higher in organic strawberries from Verona and Cesena 2007 and in organic Navelina oranges from 2007. $\delta^{18} \mathrm{O}$ values of juice water were found to be significantly higher in organic oranges Tarocco 2007, Clementine 2006 and 2008, in Spring lady peaches 2007 and in strawberries Cesena 2007, whereas organic White Queen 2006 and strawberries from Cesena 2008 had lower $\delta^{18} \mathrm{O}$. These differences can be explained on the basis of the different microclimatic conditions of the production area or the different density of cultivation and growing of the plants in the two agricultural regimes. These factors may effect the evapotranspiration process which is known to be followed by significant differences in isotopic fractionation. As observed for $\delta^{13} \mathrm{C}$, cultivar, year and site of production are however more significant than the production regime in influencing both $\delta^{18} \mathrm{O}$ and $\delta^{2} \mathrm{H}$ (Table 2-4) as expected because the latter are known to be good indicators of geographical origin (Kelly, Heaton \& Hoogewerff, 2005; Camin et al., 2008).

The $\delta^{34} \mathrm{~S}$ values of pulp were found not to be significantly affected by the production regime, but by the cultivar, site and year of production and by the interaction of site and production system for strawberries (Table 4). In fact, considering the sites separately (Table 4), organic and conventional strawberries showed significantly different $\delta^{34} \mathrm{~S}$, but with opposite trends: they were higher in organic strawberries from Cesena 2007 and Metaponto 2007, but lower in those from Verona 2007. It appears that $\delta^{15} \mathrm{~N}$ is the only isotopic parameter that can be reliably used as a marker of organic fruits, because it discriminates the organic from the conventional fruits in most cases, and is less influenced by other variables, such as cultivar, year and site of production. This discrimination capability is reliable, if organic fertiliser is not used in the conventional regime as in the majority of cases or if in the organic production the soil has not been managed with crop rotation and derived from green manure based on leguminous ( $\mathrm{N}$-fixing) plants.

Considering the real minimum value as a threshold value, we found a limiting value of $\delta^{15} \mathrm{~N}$ of $4.6 \%$ for organic oranges, $0.4 \%$ for peaches and $1.8 \%$ for strawberries from Verona (Figure 1 ). However, up to $77 \%$ for oranges, $46 \%$ for peaches and $66 \%$ for strawberries of the conventional counterparts have $\delta^{15} \mathrm{~N}$ values higher than these limits. This overlapping is due to the fact that the $\delta^{15} \mathrm{~N}$ of plants depend also on the soil $\delta^{15} \mathrm{~N}$ composition, that is influenced by many factors such as climatic condition of the area, general soil conditions, long-term soil treatment and precedent land use (Bateman et al., 2007). However, even if these limits do not permit unequivocal differentiation of the organic fruits from the conventional ones, we believe that they can be an important indicator and an important starting point for a more complex analytical model capable of verifying the organic declaration on the label. It is noteworthy that considering samples of a single cultivar (Figure 1), the separation of organic from conventional fruits improves significantly, because other factors play a less significant role.

The other isotopic parameters were shown to be less significant in the separation of organic from conventional fruits, because they were more significantly affected by cultivar, year and site of production and showed opposite trends. However, in the case of $\delta^{18} \mathrm{O}$ of clementine juice water it was found to be one of the few parameters capable of distinguishing the organic from the 
conventional fruits. They could therefore be useful if combined with $\delta^{15} \mathrm{~N}$ or other variables in order to improve the discrimination between organic and conventional products.

\section{Chemical parameters}

Ascorbic acid and Total Soluble Solids (TSS) were found to be the most significant parameters for discriminating organic from conventional fruits (Table 2-4), because they were significant $(\mathrm{p}<0.05)$ for both the species analysed, citrus and strawberry. Examination of the Tukey's test results (Tables 2-4) shows that organic Tarocco oranges of both the years, clementine 2006 and strawberries from Cesena 2007, Verona 2007 and Metaponto have a significantly $(\mathrm{p}<0.05)$ higher ascorbic acid content than the conventional equivalents. TSS was significantly higher in organic Tarocco oranges in 2006 and in strawberries from Metaponto, but lower in strawberry from Cesena in 2008. Besides the agricultural regime, ascorbic acid was influenced by year and cultivar, whereas TSS was affected also by cultivar and site of production. Ascorbic acid was (in addition to $\delta^{18} \mathrm{O}$ ) the only parameter found significant $(\mathrm{p}<0.01)$ for clementine.

Moreover, titratable acidity and citric acid content can significantly $(p<0.001)$ differentiate organic from conventional strawberries (Table 4). Citric acid was significantly higher in most of the organic strawberries (Cesena 2007, Verona 2007, Metaponto 2007 and 2008), some of which (Verona 2007, Metaponto 2007 and 2008) also possessed higher titratable acidity (Table 4). On the other hand, titratable acidity was not significant for oranges.

Flesh firmness in strawberry as well as total nitrogen in oranges and anthocyanin contents of peel and antioxidant activity of pulp in peaches, was significantly affected by the agricultural regime $(p<0.01)$, even if the other variability factors were often more significant.

332 The other quality parameters, when significant, often possessed opposite trends. For example synephrine was able to differentiate organic from conventional oranges but with an opposite trend; in fact it was not always lower in organic fruits, as observed elsewhere (Rapisarda et al., 2005), but it was significantly $(\mathrm{p}<0.05)$ higher in organic oranges Tarocco 06. A similar trend is evident for the sugar content of strawberries.

Of the chemical characteristics, the N-poor compounds (that contribute to TSS) with an antioxidant activity (ascorbic acid, phenolic compounds) were found to be the most significant markers of organic fruits. They are generally higher in organic fruits because of the lower $\mathrm{N}$ availability and higher pathogen pressure of the plants, which may result in the bio-synthesis of N-poor and endogenous plant defence compounds (Carbonaro et al., 2002)

It is difficult to define a threshold limit for these parameters, due to the large natural variability observed in these samples. In many cases in fact, the analytical parameters were more influenced by cultivar, year and site of production than by the agricultural regime.

\section{Combination of isotopic and chemical parameters}

Because the combination of several analytical parameters has previously shown, in many cases, the potential to improve the discrimination capability between food origin populations (Camin et al., 2010), we applied a multivariate canonical discriminate analysis to the most significant isotopic and quality variables, in order to establish if it is possible to enhance the separation between organic and conventional fruits. The canonical discriminant analysis (CDA) is a statistical analysis that maximises the difference between groups by means of a combination of the variables. It was applied only to orange and strawberry samples for which several analytical parameters were found significant and for which the number of samples for different groups was more consistent.

For oranges, the CDA was applied to $\delta^{15} \mathrm{~N}$, TSS, Ascorbic acid and Total N, that are the significant parameters highlighted by the ANOVA test (Table 2). One canonical variable (CAN) was identified loaded negatively with $\delta^{15} \mathrm{~N}$ (standardised coefficient: -0.86), TSS (-0.35) and Ascorbic acid (0.19 ) and positively with Total N (0.39). The model was able to discriminate the $85 \%$ of the 42 organic and of the 52 conventional samples, as proved by applying the classification discriminant analysis also following a cross-validation procedure (Camin et al., 2010). The cross-validation 361 procedure consisted of using a subset of the analyzed samples as 'unknowns' to validate the model 
built on the basis of the remaining cases. In detail, 3 different sets of samples (around $10 \%$ of the original database) were removed from the data, and each time the model was calculated on the remaining cases and was validated with all the samples (including the excluded ones). Crossvalidation was applied to test the stability of the statistical model and its predictive discrimination power for unknown test samples.

In the case of strawberry, $\delta^{13} \mathrm{C}, \delta^{15} \mathrm{~N}, \mathrm{FF}, \mathrm{TSS}, \mathrm{TA}$, ascorbic acid and citric acid were taken into account for the multivariate canonical discriminant analysis $\left(\delta^{2} \mathrm{H}\right.$ was not included because it was measured in a reduced number of samples). One canonical variable (CAN) was identified mainly loaded positively with $\delta^{15} \mathrm{~N}(0.78)$, titratable acidity $(0.76)$ and ascorbic acid $(0.45)$ and negatively with TSS (-0.25). The classification discriminant analysis correctly reclassified $68 \%$ of the 80 organic and $77 \%$ of the 78 conventional samples. The percentages of correct reclassification were confirmed also adopting the cross-validation test.

Therefore, the combination of many variables was able to improve the discrimination between organic and conventional fruits, even if did not achieve a total (100\%) separation between them. If we reduce the variability factors, e.g. grouping the samples according to their cultivar (orange) or the origin (strawberry), the separation between organic and conventional fruits becomes more realistic. The Canonical Discriminant Analysis was applied to all the isotopic and quality parameters, selecting the most significant ones for the discrimination between origin/cultivar and agricultural regime, by performing a forward stepwise analysis ( $\mathrm{F}$ to enter $=5 ; \mathrm{T}=0.01$; number of steps $=$ number of variables): the variables were included in the model one by one, choosing at each step the variable that made the most significant additional contribution to the discrimination (with the largest $F$ value). The variable was excluded from the model if it was redundant $(\mathrm{T}<0.01)$.

Considering oranges, the stepwise discriminant analysis applied to 54 samples (complete dataset) selected for the discrimination of the 2 cultivars and the 2 agricultural regimes in order of significance: $\delta^{18} \mathrm{O}$, ascorbic acid, $\delta^{15} \mathrm{~N}$, synephrine and $\delta^{13} \mathrm{C}$. Three independent discriminant functions (CANs) were computed: CAN1 (93\%) loaded mainly negatively with $\delta^{18} \mathrm{O}(-0.80)$ and $\delta^{13} \mathrm{C}(-0.49)$ and positively with ascorbic acid (0.61) and synephrine $(0.65)$; RAD2 (6\%) positively determined mainly by $\delta^{15} \mathrm{~N}(0.97)$ and negatively by $\delta^{13} \mathrm{C}(-0.48)$. The reclassification discriminant analysis correctly reclassified $89 \%$ of the samples, reclassifying $100 \%$ of the 24 conventional Tarocco oranges and of the 6 organic Navelina, 83\% of the 6 conventional Navelina (1 sample was misclassified as organic Navelina) and $72 \%$ of the 19 organic Tarocco (5 samples were misclassified as conventional Tarocco). The percentage of correct reclassification was confirmed after adopting the cross-validation procedure, excluding from the model each time 6 samples of Tarocco oranges ( 3 organic and 3 conventional) and 2 of Navelina ( 1 organic and 1 conventional). For strawberry, $\delta^{15} \mathrm{~N}, \mathrm{TA}, \delta^{18} \mathrm{O}, \delta^{13} \mathrm{C}, \mathrm{FF}, \Delta \mathrm{E}$, sucrose and ascorbic acid were selected for the discrimination of the 3 origins and the 2 agricultural regimes $\left(\delta^{2} \mathrm{H}\right.$ and $\delta^{34} \mathrm{~S}$ were not included because measured only in samples of 2007). The CDA computed 5 CANs: CAN1 (69\%) loaded negatively with $\delta^{13} \mathrm{C}(-0.75), \delta^{18} \mathrm{O}(-0.73)$, FF $(-0.60)$, TA $(-0.58)$ and positively mainly with $\delta^{15} \mathrm{~N}$ (0.43); CAN2 (16\%) determined positively mainly by $\delta^{15} \mathrm{~N}(0.80), \Delta \mathrm{E}(0.66)$, TA $(0.66)$, ascorbic acid (0.42); CAN3 (10\%) mainly positively by $\Delta \mathrm{E}(0.57)$, TA $(0.44)$ and negatively by $\delta^{18} \mathrm{O}(-0.73)$, $\delta^{15} \mathrm{~N}(-0.56), \delta^{13} \mathrm{C}(-0.63)$. The reclassification discriminant analysis correctly reclassified $86 \%$ of the samples, reclassifying $100 \%$ of the 20 organic Metaponto samples, $96 \%$ of the 22 conventional Verona (1 samples misclassified as conventional Cesena), $90 \%$ of the 20 conventional Metaponto ( 1 as organic Cesena and 1 as organic Metaponto), $83 \%$ of the 24 organic Verona ( 1 as conventional Cesena and 3 as conventional Verona), $81 \%$ of the 36 conventional Cesena ( 7 as organic Cesena) and $75 \%$ of the 36 organic Cesena ( 6 as conventional Cesena, 2 as conventional Metaponto and 1 as organic Verona). The percentage of correct reclassification was confirmed adopting the crossvalidation test.

Considering the strawberries produced in a single year (2007) grouped by both production system and geographical origin, $\delta^{34} \mathrm{~S}, \Delta \mathrm{E}, \mathrm{TA}, \delta^{2} \mathrm{H}, \delta^{18} \mathrm{O}, \delta^{15} \mathrm{~N}$, fructose and sucrose were selected and 5 CANs were computed. The combination of the first two canonical variables CAN1 (77\%) and 
CAN2 accounted for $91 \%$ of variability (scores plot shown in Figure 2). CAN1 was loaded negatively mainly with $\delta^{34} \mathrm{~S}(-0.88)$, sucrose $(-0.39)$ and $\delta^{15} \mathrm{~N}(-0.31)$ and positively with $\delta^{18} \mathrm{O}$ $(0.41)$ and $\delta^{2} \mathrm{H}(0.38)$, whereas CAN2 was mainly determined positively by $\delta^{18} \mathrm{O}(0.79), \delta^{2} \mathrm{H}(0.73)$, fructose $(0.72)$ and negatively by sucrose $(-0.77)$ and $\Delta \mathrm{E}(-0.52)$. It is evident (Figure 2$)$ that the model is able to discriminate completely the geographical origin of strawberry and, inside each area, it allows to distinguish also the agricultural regime. The reclassification discriminant analysis correctly reclassified $98 \%$ of the samples also with the cross-validation procedure, reclassifying correctly all the groups except for organic Cesena $(88 \%$, with 2 samples misclassified as conventional Cesena).

To summarise, for oranges and strawberries, on the basis of the number or type of groups, different parameters were selected as significant for the discrimination between the groups (to separate only the agricultural regime or also cultivar or production site). Of the parameters, $\delta^{15} \mathrm{~N}$ was always significant and ascorbic acid was significant in most of the cases.

For peaches, considering the 2 cultivars separately, an optimal discrimination between organic and conventional fruits was achieved with $\delta^{15} \mathrm{~N}$ (Figure 1). For clementine other analytical markers are needed in order to characterise the organic fruits.

\section{Conclusions}

The stable isotope ratio of nitrogen (expressed as $\delta^{15} \mathrm{~N}$ ), ascorbic acid and total soluble solids (TSS) were found to be the most significant isotopic and chemical markers for distinguishing between organic and conventional fruits. It was difficult to define general threshold limits because most of the markers are influenced not only by the agricultural system, but also by fruit specie, cultivar, year and site of production. Nevertheless, these analytical measurements when applied with sufficient background knowledge can provide extremely useful intelligence to corroborate paper traceability or pesticide residue analysis information at the field or retail level.

By combining isotopic and quality markers and by applying multivariate discriminant statistical tests, organic and conventional fruits were distinguishable, in particular when removing variability factors such as site, cultivar and year of production. In order to use these analytical parameters for verifying the authenticity of commercial organic fruits, it is necessary to previously analyse a significant number of authentic organic samples representative of the production and to apply multivariate statistical tests in order to select the most significant parameters on which to build the most suitable statistical model.

\section{Acknowledgment:}

This work was funded by the Ministry of Agricultural, Food and Forestry Policy, within the framework of the Project "BIOMARKERS" (DM 91461/06-09-2005) entitled "New markers for the traceability of organic fruits". 


\section{References}

Bateman, A. S., \& Kelly, S. D. (2007). Fertilizer nitrogen isotope signatures. Isotopes in Environmental and health studies, 43(3), 237-247 DOI: 10.1080/10256010701550732

Bateman, A. S., Kelly, S. D., \& Woolfe, M. (2007). Nitrogen Isotope Composition of Organically and Conventionally Grown Crops. Journal of Agricultural and Food Chemistry, 55, 2664-2670. DOI: $10.1021 /$ jf0627726

Bateman, A. S., Kelly, S. D., \& Jickells, T. D. (2005). Nitrogen Isotope Relationships between Crops and Fertilizer: Implications for Using Nitrogen Isotope Analysis as an Indicator of Agricultural Regime. Journal of Agricultural and Food Chemistry, 53, 5760-5765. DOI: 10.1021/jf050374h

Brandt, K., \& Molgaard, J. P. (2001). Organic agriculture: does it enhance or reduce the nutritional value of plant foods. Journal of the Science of Food and Agriculture, 81, 924-931. DOI: $10.1002 /$ jsfa. 903

Brand-Williams, W., Cuvelier, M. E., \& Berset, C. (1995). Use of free radical method to evaluate antioxidant activity. Lebensmittel-Wissenschaft und-Technologie, 28, 25-30. DOI: 10.1016/S00236438(95)80008-5

Camin, F., Moschella, A., Miselli, F., Parisi, B., Versini, G., Ranalli, P., \& Bagnaresi, P. (2007). Evaluation of markers for the traceability of potato tubers grown in an organic versus conventional regime. Journal of the Science of Food and Agriculture, 87, 1330-1336. DOI: 10.1002/jsfa.2853

Camin, F., Perini, M., Colombari, G., Bontempo, L., \& Versini, G. (2008). Influence of dietary composition on the carbon, nitrogen, oxygen and hydrogen stable isotope ratios of milk. Rapid communications in mass spectrometry, 22(11), 1690-1696. http://dx.doi.org/10.1002/rcm.3506

Camin, F., Larcher, R., Nicolini, G., Bontempo, L., Bertoldi, D., Perini, M., Schlicht, C., Schellenberg, A., Thomas, F., Heinrich, K., Voerkelius, S., Horacek, M., Ueckermann, H., Froeschl, H., Wimmer, B., Heiss, G., Baxter, M., Rossmann, A., \& Hoogewerff J. (2010) Isotopic and elemental data for tracing the origin of European olive oils. Journal of Agricultural and Food Chemistry, 58, 570-577. DOI:10.1021/jf902814s

Carbonaro, M., Mattera, M., Nicoli, S., Bergamo, P., \& Cappelloni, M. (2002). Modulation of antioxidant compounds in organic vs conventional fruit (peach, Prunus persica L., and pear, Pyrus communis L.). Journal of Agricultural and Food Chemistry, 50, 5458-5462. DOI: $10.1021 / \mathrm{jf0} 202584$

Choi, W. J., Lee, S. M., Ro, H. M., Kim, K. C., \& Yoo, S. H. (2002). Natural ${ }^{15} \mathrm{~N}$ abundances of maize and soil amended with urea and composition pig manure. Plant and Soil, 245, 223-232. DOI: 10.1016/S0038-0717(03)00199-8

Choi, W. J., Ro, H. M., \& Hobbie, E. A. (2003). Patterns of natural ${ }^{15} \mathrm{~N}$ in soils and plants from chemically and organically fertilized uplands. Soil Biology \& Biochemistry, 35, 1493-1500. DOI: 10.1016/S0038-0717(03)00246-3

Dangour, A. D., Dodhia, S. K., Hayter, A., Allen, E., Lock, K., \& Uauy, R. (2009) Nutritional quality of organic foods: a systematic review. American Journal of Clinical Nutrition, 90, 680 685. DOI: 10.3945/ajen.2009.28041 
Flores, P., Fenoll, J., \& Hellín, P. (2007) The Feasibility of Using ${ }^{15} \mathrm{~N}$ and ${ }^{13} \mathrm{C}$ Values for Discriminating between Conventionally and Organically Fertilized Pepper (Capsicum annuum L.). Journal of Agricultural and Food Chemistry, 55, 5740 - 5745. DOI: 10.1021/jf0701180

Georgi, M., Voerkelius, S., Rossmann, A., Grassmann, J., \& Schnitzler, W. H. (2005). Multielement isotope ratios of vegetables from integrated and organic production. Plant and Soil, 275, 93-100. DOI: 10.1007/s11104-005-0258-3

Hogberg, P., Johannosson, C., Hog, M., Nasholm, T., \& Hallgren J. E. (1995) Measurement of abundances of $\mathrm{N}^{-15}$ and $\mathrm{C}_{-}{ }^{13}$ as tools in retrospective studies of $\mathrm{N}$ balances and water-stress in forest. A discussion of preliminary-results. Plant and Soil, 169, 125-133. DOI: 10.1007/BF00029321

Kelly, S. D., \& Bateman, A. S. (2009) Comparison of mineral concentrations in commercially grown organic and conventional crops tomatoes (Lycopersicon esculentum) and lettuces (Lactuca sativa). Food Chemistry, 119(2), 738-745. doi: 10.1016/j.foodchem.2009.07.022

Kelly, S. D., Heaton, K., \& Hoogewerff, J. (2005) Tracing the geographical origin of food: The application of multi-element and multi-isotope analysis. Trends in Food Science and Technology, 16, 555-567. DOI: 10.1016/j.tifs.2005.08.008

Kimball, D. A. (1991). Citrus Processing Quality Control and Technology. AVI/Van Nostrand Reinhold (pp. 102-116). New York.

Lairon, D. (2009) Nutritional quality an safety of organic food. A review. Agronomy for Sustainable Development. DOI: 10.1051/agro/2009019, www.agronomy-journal.org

Nakano, A., Uehara, Y., \& Yamauchi, A. (2003). Effect of organic and inorganic fertigation on yields, $\delta^{15} \mathrm{~N}$ values, and $\delta^{13} \mathrm{C}$ values of tomato (Lycopersicon esculentum Mill.cv.Saturn). Plant and Soil, 255, 343-349. DOI: 10.1023/A:1026180700963

O’Leary, M. H. (1995) Environmental Effects on Carbon Isotope Fractionation in Terrestrial Plant. In Stable Isotopes in the Biosphere, Wada, E., Yoneyama, T., Mingawa, M., Ando, T., Fry, B.D.; Kyoto University Press: Kyoto; 78-91.

Otsuchi, B., Sanriku, J., Carvalho, M. C., Hayashizaki, K., \& Ogawa, H. (2008). Sulfur stable isotopes indicate the source of sinking materials in a coastal bay. Journal of Oceanography, 64, 705 -712. DOI: $10.1007 / \mathrm{s} 10872-008-0059-4$

Perini, M., Camin, F., Bontempo, L., Rossmann, A., \& Piasentier, E. (2009). Multielement (H, C, $\mathrm{N}, \mathrm{O}, \mathrm{S})$ stable isotope characteristics of lamb meat from different Italian regions. Rapid Communications in Mass Spectrometry, 23 (16), 2573 - 2585. DOI: 10.1002/rcm.4140

Rapisarda, P., Calabretta, M. L., Romano, G., \& Intrigliolo, F. (2005). Nitrogen metabolism components as a tool to discriminate between organic and conventional citrus fruits. Journal of Agricultural and Food Chemistry, 53, 2664-2669. DOI: 10.1021/jf048733g

Rapisarda P., \& Intelisano S. (1996). Sample preparation for ascorbic acid analysis of pigmented orange juices. Italian Journal of Food Science, 3, 251-256 
Rapisarda, P., Camin, F., Fabroni S., Perini M., Torrisi B., \& Intrigliolo, F. (2010) Influence of Different Organic Fertilizers on Quality Parameters and the $\delta^{15} \mathrm{~N}, \delta^{13} \mathrm{C}, \delta^{2} \mathrm{H}, \delta^{34} \mathrm{~S}$, and $\delta^{18} \mathrm{O}$ Values of Orange Fruit (Citrus sinensis L. Osbeck). Journal of Agriculture and Food Chemistry, 58(6), 3502-3506. DOI: 10.1021/jf903952v

561

562

563

564

565

566

567

568

569

570

571

572

573

574

575

576

577

578

579

580

581

582

583

584

Rogers, K. M. (2008). Nitrogen isotopes as a screening tool to determine the growing regimen of some organic and nonorganic supermarket produce from New Zealand. Journal of Agricultural and Food Chemistry, 56, 4078-4083. http://dx.doi.org/10.1021/jf800797w

Schmidt, O., Quilter, J. M., Bahar, B., Moloney, A. P., Scrimgeour, C. M., \& Begley, I. S. (2005) Inferring the origin and dietary history of beef from $\mathrm{C}, \mathrm{N}$ and $\mathrm{S}$ stable isotope ratio analysis. Food Chemistry, 91, 545-549. DOI: 10.1016/j.foodchem.2004.08.036

Schmidt, H. L., Rossmann, A., Voerkelius, S., Schnitzler, W. H., Georgi, M., Grassmann, J., Zimmermann, G., \& Winkler, R. (2005). Isotope characteristics of vegetables and wheat from conventional and organic production. Isotopes in Environmental and Health Studies, 41, 223-8. DOI: $10.1080 / 10256010500230072$

Swain, T., \& Hillis, W. E. (1959). The phenolic constituents of Prunus domestica. I. - The quantitative analysis of phenolic constituents. Journal of the Science of Food and Agriculture, 10, 63-68.

Wassenaar, L. I., \& Hobson, K. A. (2003). Comparative equilibration and online technique for determination of non-exchangeable hydrogen of keratins for animal migration studies. Isotopes in Environmental and Health Studies, 39, 1-7. DOI: 10.1080/1025601031000096781 
587 Figure 1: Box plot whisker of $\delta^{15} \mathrm{~N}$ values of organic and conventional oranges, peaches and 588 strawberries (from Verona)

Figure 2: Canonical Discriminant analysis of isotopic and quality parameters of organic and 592 conventional strawberries produced in 3 Italian areas in 2007: plot of the first two canonical 593 
Figure 1: Box plot whisker of $\delta^{15} \mathrm{~N}$ values of organic and conventional oranges, peaches and strawberries (from Verona)

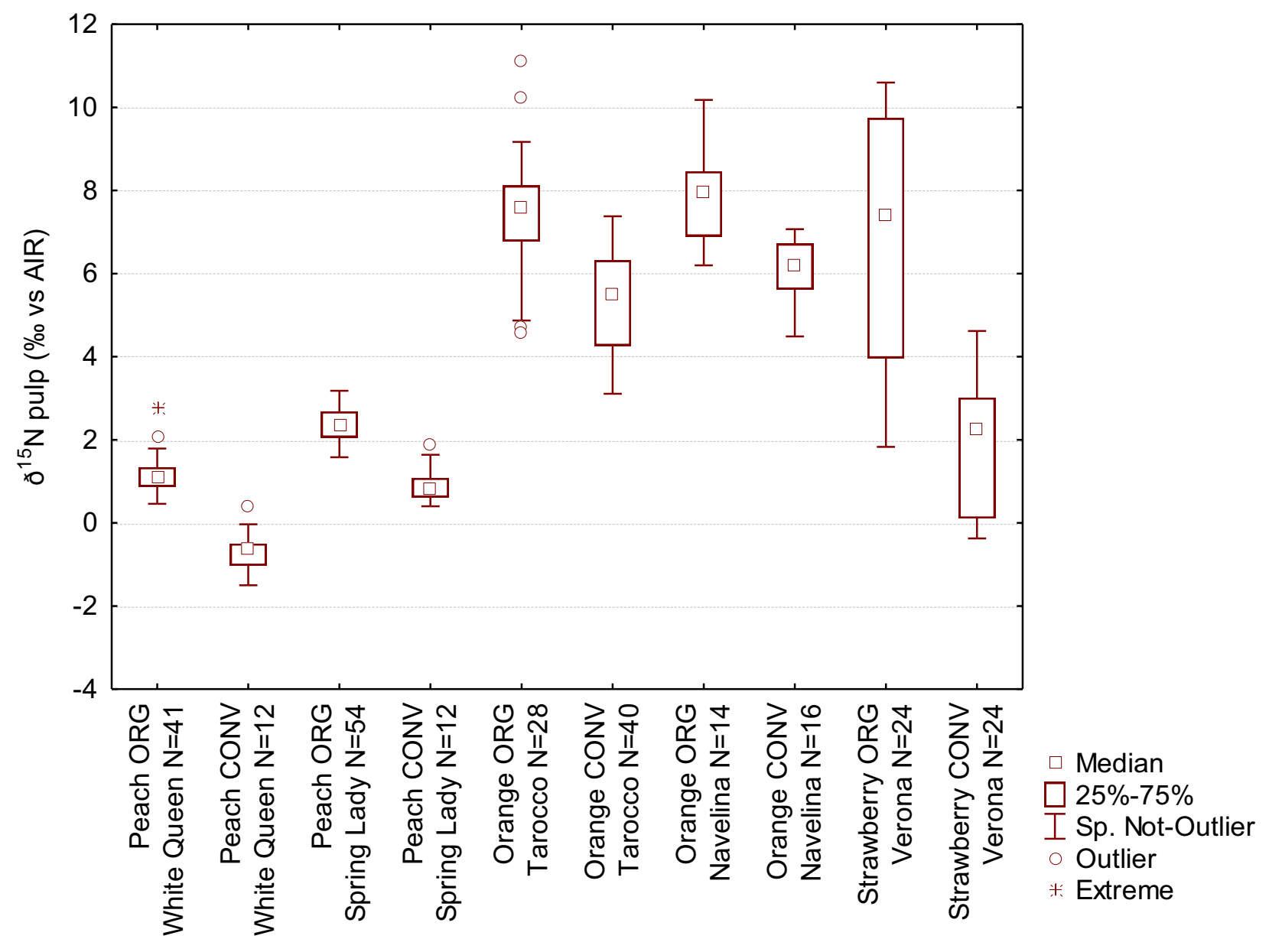


Figure 2: Canonical Discriminant analysis of isotopic and quality parameters of organic and conventional strawberries produced in 3 Italian areas in 2007: plot of the first two canonical variables

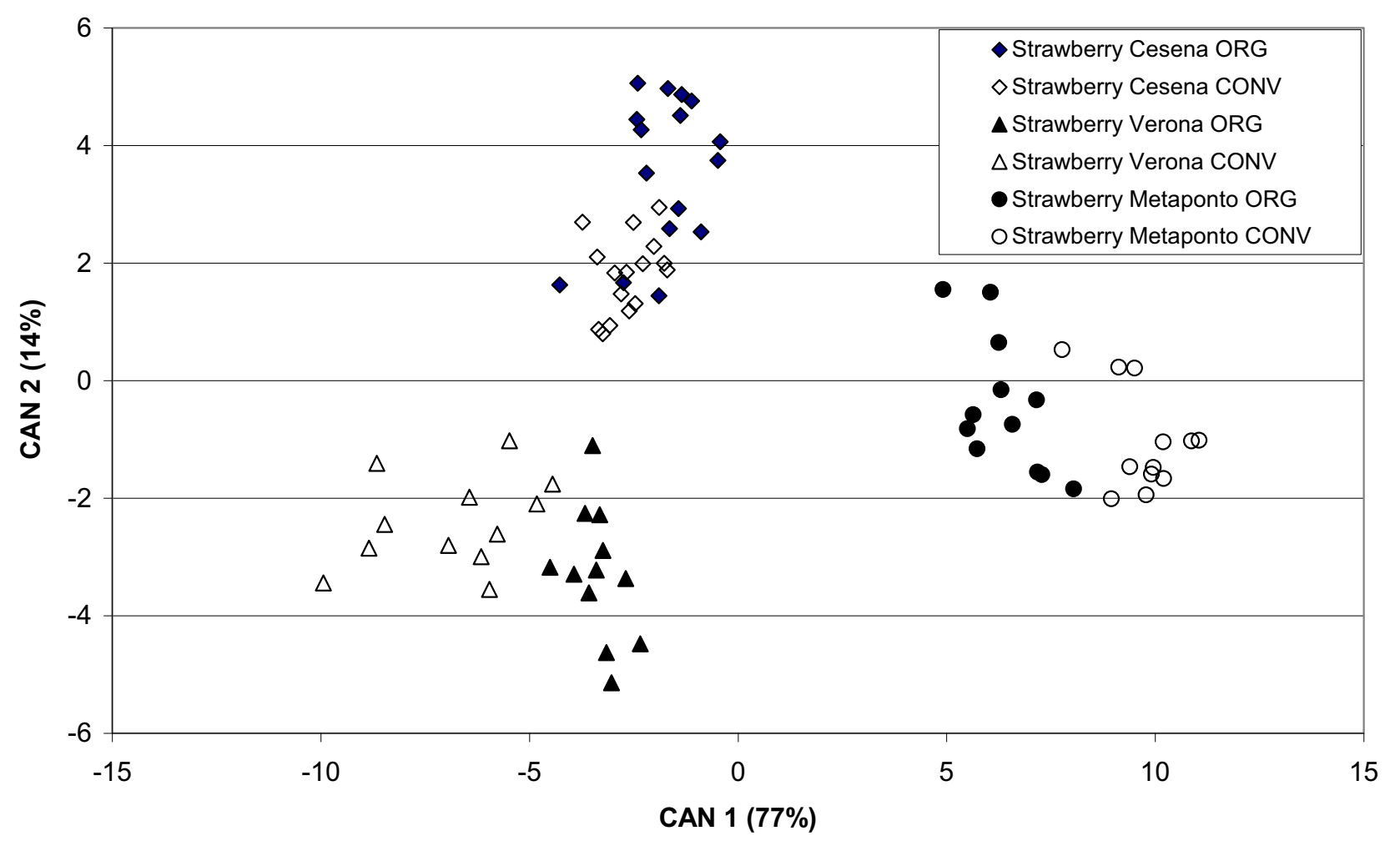


Table 1: Samples

\begin{tabular}{|c|c|c|c|c|c|c|}
\hline type of fruit & variety & year & production site & $\begin{array}{l}\text { type of } \\
\text { sample }\end{array}$ & $\begin{array}{c}\mathrm{N} . \text { of } \\
\text { organic } \\
\text { samples }\end{array}$ & $\begin{array}{c}\text { N. of } \\
\text { conventional } \\
\text { samples }\end{array}$ \\
\hline Orange & Tarocco & 2006 & Sicily & commercial & 18 & 24 \\
\hline Orange & Tarocco & 2007 & Sicily & commercial & 10 & 16 \\
\hline Orange & Navelina & 2007 & Sicily & commercial & 14 & 16 \\
\hline Clementine & & 2006 & Calabria & commercial & 16 & 7 \\
\hline Clementine & & 2007 & Calabria & commercial & 6 & 6 \\
\hline Clementine & & 2008 & Calabria & commercial & 9 & 8 \\
\hline Peach & Spring lady & 2006 & Rome, Lazio & experimental & 6 & 2 \\
\hline Peach & Spring lady & 2007 & Rome, Lazio & experimental & 24 & 6 \\
\hline Peach & Spring lady & 2008 & Rome, Lazio & experimental & 24 & 4 \\
\hline Peach & White Queen & 2006 & Rome, Lazio & experimental & 6 & 2 \\
\hline Peach & White Queen & 2007 & Rome, Lazio & experimental & 11 & 4 \\
\hline Peach & White Queen & 2008 & Rome, Lazio & experimental & 24 & 6 \\
\hline Strawberry & Nora & 2006 & Cesena, Emilia Romagna & experimental & 2 & 2 \\
\hline Strawberry & Nora & 2007 & Cesena, Emilia Romagna & experimental & 4 & 4 \\
\hline Strawberry & Nora & 2008 & Cesena, Emilia Romagna & experimental & 4 & 4 \\
\hline Strawberry & Nora & 2007 & Verona, Veneto & commercial & 4 & 4 \\
\hline Strawberry & Nora & 2008 & Verona, Veneto & commercial & 4 & 4 \\
\hline Strawberry & Nora & 2007 & Metaponto, Basilicata & commercial & 4 & 4 \\
\hline Strawberry & Patty & 2006 & Cesena, Emilia Romagna & experimental & 1 & 1 \\
\hline Strawberry & Patty & 2007 & Cesena, Emilia Romagna & experimental & 4 & 4 \\
\hline Strawberry & Patty & 2008 & Cesena, Emilia Romagna & experimental & 4 & 4 \\
\hline Strawberry & Patty & 2007 & Verona, Veneto & commercial & 4 & 4 \\
\hline Strawberry & Patty & 2008 & Verona, Veneto & commercial & 4 & 4 \\
\hline Strawberry & Record & 2006 & Cesena, Emilia Romagna & experimental & 2 & 2 \\
\hline Strawberry & Record & 2007 & Cesena, Emilia Romagna & experimental & 4 & 4 \\
\hline Strawberry & Record & 2008 & Cesena, Emilia Romagna & experimental & 4 & 4 \\
\hline Strawberry & Queen Elisa & 2006 & Cesena, Emilia Romagna & experimental & 1 & 1 \\
\hline Strawberry & Queen Elisa & 2007 & Cesena, Emilia Romagna & experimental & 4 & 4 \\
\hline Strawberry & Queen Elisa & 2008 & Cesena, Emilia Romagna & experimental & 4 & 4 \\
\hline Strawberry & Eva & 2007 & Verona, Veneto & commercial & 4 & 4 \\
\hline Strawberry & Eva & 2008 & Verona, Veneto & commercial & 4 & 4 \\
\hline Strawberry & Candonga & 2007 & Metaponto, Basilicata & commercial & 4 & 4 \\
\hline Strawberry & Candonga & 2008 & Metaponto, Basilicata & commercial & 4 & 4 \\
\hline Strawberry & Camarosa & 2007 & Metaponto, Basilicata & commercial & 4 & 4 \\
\hline Strawberry & Camarosa & 2008 & Metaponto, Basilicata & commercial & 4 & 4 \\
\hline
\end{tabular}


Table 2: Significance of the influence of agricultural regime (agr. reg.), cultivar and year on isotopic and chemical characteristics and mean and standard deviation of citrus samples grouped by cultivar and year. FW: fruit weight; JY: juice yield; TSS: total soluble solid; TA: titratable acidity; Total N: total nitrogen in juice; Syineph.: Syinephrine. N: number of samples measured. ns: not significant; *: significant, $\mathrm{p}<0.05$; $* *$ : significant, $\mathrm{p}<0.01$, ***: significant, $\mathrm{p}<0.001$. Significantly different mean values (HSD Tukey's, $\mathrm{p}<0.05$ ) between organic and conventional fruits are highlighted with letters ' $a$ ' and ' $b$ '.

\begin{tabular}{|c|c|c|c|c|c|c|c|c|c|c|c|c|c|c|c|c|c|c|}
\hline & & $\begin{array}{l}\delta^{13} \mathrm{C} \\
\text { pulp } \\
\% \text { \% } \mathrm{V}- \\
\text { PDB }\end{array}$ & $\begin{array}{r}\delta^{15} \wedge \\
\text { pulp } \\
\% \circ \mathrm{Al}\end{array}$ & & $\begin{array}{c}\delta^{18} \\
\text { juic } \\
\% \text { o } \\
\text { SMO }\end{array}$ & & $\begin{array}{c}\text { SD pulp } \\
\% \text { V- } \\
\text { SMOW }\end{array}$ & $\begin{array}{c}\delta^{34} S \\
\text { pulp } \\
\% \text { o } \\
\text { CDT }\end{array}$ & $\begin{array}{r}F Y \\
g\end{array}$ & & $\begin{array}{l}J Y \\
\%\end{array}$ & $\begin{array}{c}\text { TSS } \\
\% \\
\end{array}$ & $\begin{array}{l}\text { TA \% } \\
\text { citric } \\
\text { acid }\end{array}$ & $\mathrm{pH}$ & $\begin{array}{r}\text { VIT } \\
\mathrm{mg} / 100\end{array}$ & $\begin{array}{l}\mathrm{C} \\
\mathrm{OmL}\end{array}$ & $\begin{array}{c}\text { Total N } \\
\mathrm{mg} / \mathrm{L}\end{array}$ & $\begin{array}{c}\text { Syineph. } \\
\text { mg/L }\end{array}$ \\
\hline \multirow{4}{*}{ Orange } & agr. reg. (org/conv) & ns & $* * *$ & & $\mathrm{~ns}$ & & ns & ns & ns & & ns & $* *$ & ns & ns & * & & $\star *$ & ns \\
\hline & cultivar & $* * *$ & * & & $* * *$ & & $* * *$ & $* * *$ & ns & & $* *$ & ** & ns & ** & $* * *$ & & * & $* * *$ \\
\hline & year & $* * *$ & ns & & *** & & *** & $* * *$ & ns & & ns & $* * *$ & ns & $* * *$ & *** & & $* * *$ & ns \\
\hline & agr. reg. $\mathrm{X}$ cultivar & ns & ns & & ns & & $* *$ & ns & * & & ns & ns & ns & ns & ns & & ns & ns \\
\hline & mean & -25.6 & 7.3 & $\mathrm{a}$ & 0.6 & & -43 & 6.2 & 191 & $\mathrm{~b}$ & 51 & 11.4 & 1.2 & 3.6 & 85 & $\mathrm{a}$ & 681 & 42 \\
\hline Tarocco 2006 & std dev & 1.0 & 1.9 & & 0.5 & & 5 & 1.7 & 30 & & 4 & 1.0 & 0.2 & 0.1 & 8 & & 99 & 5 \\
\hline \multirow{2}{*}{ ORGANIC } & $\mathrm{N}$ & 18 & 18 & & 18 & & 18 & 18 & 18 & & 18 & 18 & 18 & 18 & 18 & & 18 & 18 \\
\hline & mean & -25.3 & 5.4 & $\mathrm{~b}$ & 0.7 & & -40 & 7.3 & 214 & a & 50 & 10.9 & 1.2 & 3.6 & 78 & $\mathrm{~b}$ & 736 & 38 \\
\hline Tarocco 2006 & std dev & 0.6 & 1.1 & & 0.7 & & 6 & 2.3 & 35 & & 7 & 0.9 & 0.2 & 0.1 & 7 & & 124 & 5 \\
\hline \multirow[t]{2}{*}{ CONVENTIONAL } & $\mathrm{N}$ & 24 & 24 & & 24 & & 24 & 24 & 24 & & 24 & 24 & 24 & 24 & 24 & & 24 & 24 \\
\hline & mean & -24.7 & 7.6 & $a$ & 2.2 & $a$ & & & 230 & & 53 & 12.5 & 1.2 & 3.5 & 79 & $a$ & 783 & 41 \\
\hline Tarocco 2007 & std dev & 0.6 & 0.6 & & 0.8 & & & & 48 & & 4 & 1.2 & 0.2 & 0.2 & 10 & & 88 & 7 \\
\hline \multirow[t]{2}{*}{ ORGANIC } & $\mathrm{N}$ & 10 & 10 & & 10 & & & & 10 & & 10 & 10 & 10 & 10 & 10 & & 10 & 10 \\
\hline & mean & -24.7 & 5.1 & $\mathrm{~b}$ & 1.5 & $\mathrm{~b}$ & & & 209 & & 55 & 11.6 & 1.3 & 3.4 & 70 & $\mathrm{~b}$ & 801 & 51 \\
\hline Tarocco 2007 & std dev & 0.8 & 1.5 & & 0.5 & & & & 34 & & 4 & 1.6 & 0.2 & 0.2 & 11 & & 130 & 13 \\
\hline \multirow[t]{2}{*}{ CONVENTIONAL } & $\mathrm{N}$ & 16 & 16 & & 16 & & & & 16 & & 16 & 16 & 16 & 16 & 16 & & 16 & 12 \\
\hline & mean & -24.3 & 7.9 & $a$ & 3.5 & & -28 & 4.6 & 218 & & 47 & 12.7 & 1.3 & 3.4 & 72 & & 667 & 23 \\
\hline Navelina 2007 & std dev & 0.2 & 1.3 & & 0.7 & & 2 & 2.7 & 34 & & 5 & 1.0 & 0.3 & 0.3 & 7 & & 37 & 2 \\
\hline \multirow[t]{2}{*}{ ORGANIC } & $\mathrm{N}$ & 14 & 14 & & 14 & & 9 & 14 & 14 & & 14 & 14 & 14 & 14 & 14 & & 12 & 8 \\
\hline & mean & -24.4 & 6.1 & $\mathrm{~b}$ & 3.9 & & -34 & 4.6 & 194 & & 50 & 11.9 & 1.3 & 3.4 & 69 & & 631 a & 31 \\
\hline Navelina 2007 & std dev & 0.5 & 0.8 & & 0.5 & & 6 & 2.0 & 28 & & 5 & 1.2 & 0.3 & 0.3 & 13 & & 77 & 8 \\
\hline CONVENTIONAL & $\mathrm{N}$ & 16 & 16 & & 16 & & 10 & 16 & 16 & & 16 & 16 & 16 & 16 & 16 & & 14 & 12 \\
\hline \multirow{3}{*}{ Clementine } & agr. reg. (org/conv) & ns & ns & & * & & ns & ns & ns & & ns & ns & ns & ns & ** & & & \\
\hline & year & $* *$ & ns & & $* * *$ & & * & & $* *$ & & * & ns & ns & ns & ns & & & \\
\hline & agr. reg. $X$ year & ns & ns & & ns & & ns & & ns & & ns & ns & ns & ns & ns & & & \\
\hline & mean & -27.0 & 6.6 & & 1.0 & $a$ & & 6.7 & 101 & & 46 & 12.1 & 0.9 & 3.5 & 62 & $a$ & & \\
\hline 2006 & std dev & 0.5 & 1.6 & & 0.3 & & & 2.1 & 29 & & 9 & 1.2 & 0.2 & 0.1 & 2 & & & \\
\hline \multirow{2}{*}{ ORGANIC } & $\mathrm{N}$ & 16 & 16 & & 16 & & & 14 & 16 & & 16 & 16 & 14 & 12 & 10 & & & \\
\hline & mean & -26.8 & 6.8 & & 0.5 & b & & 5.7 & 92 & & 46 & 11.4 & 0.8 & 3.7 & 57 & $\mathrm{~b}$ & & \\
\hline 2006 & std dev & 0.3 & 1.8 & & 0.4 & & & 0.9 & 27 & & 4 & 0.6 & 0.1 & 0.0 & 2 & & & \\
\hline \multirow{2}{*}{ CONVENTIONAL } & $\mathrm{N}$ & 7 & 7 & & 7 & & & 6 & 7 & & 7 & 7 & 7 & 4 & 7 & & & \\
\hline & mean & -27.1 & 7.5 & & 0.8 & & -36 & & 69 & & 45 & 11.3 & 1.1 & 3.5 & 62 & & & \\
\hline 2007 & std dev & 0.5 & 2.1 & & 0.5 & & 2 & & 4 & & 13 & 0.9 & 0.1 & 0.1 & 3 & & & \\
\hline \multirow[t]{2}{*}{ ORGANIC } & $\mathrm{N}$ & 6 & 6 & & 6 & & 6 & & 6 & & 6 & 6 & 6 & 6 & 6 & & & \\
\hline & mean & -26.8 & 6.7 & & 0.8 & & -35 & & 69 & & 50 & 11.5 & 1.1 & 3.6 & 59 & & & \\
\hline 2007 & std dev & 0.6 & 1.4 & & 0.3 & & 7 & & 9 & & 4 & 0.5 & 0.1 & 0.1 & 4 & & & \\
\hline \multirow[t]{2}{*}{ CONVENTIONAL } & $\mathrm{N}$ & 6 & 6 & & 6 & & 6 & & 6 & & 6 & 6 & 6 & 6 & 6 & & & \\
\hline & mean & -26.4 & 8.0 & & 0.4 & $a$ & -40 & & 91 & & 42 & 11.3 & 1.2 & 3.6 & 62 & & & \\
\hline 20078 & std dev & 0.7 & 1.6 & & 0.4 & & 9 & & 11 & & 5 & 1.0 & 0.6 & 0.1 & 4 & & & \\
\hline \multirow[t]{2}{*}{ ORGANIC } & $\mathrm{N}$ & 9 & 9 & & 9 & & 9 & & 9 & & 9 & 9 & 9 & 9 & 9 & & & \\
\hline & mean & -26.3 & 7.1 & & -0.2 & b & -43 & & 86 & & 37 & 11.0 & 0.9 & 3.6 & 60 & & & \\
\hline $2007 \underline{8}$ & std dev & 0.3 & 1.1 & & 0.5 & & 4 & & 6 & & 6 & 0.8 & 0.1 & 0.0 & 5 & & & \\
\hline CONVENTIONAL & $\mathrm{N}$ & 8 & 8 & & 8 & & 8 & & 8 & & 8 & 8 & 8 & 8 & 8 & & & \\
\hline
\end{tabular}


Table 3: Significance of the influence of agricultural regime (agr. reg.), cultivar and year on isotopic and chemical characteristics and mean and standard deviation of peaches samples grouped by cultivar and year. $\mathrm{N}$ : number of samples measured. ns: not significant; *: significant, $\mathrm{p}<0.05$; **: significant, $\mathrm{p}<0.01, * * *$ : significant, $\mathrm{p}<0.001$. Significantly different mean values (HSD Tukey's, $\mathrm{p}<0.05$ ) between organic and conventional fruits are highlighted with letters ' $a$ ' and ' $b$ '.

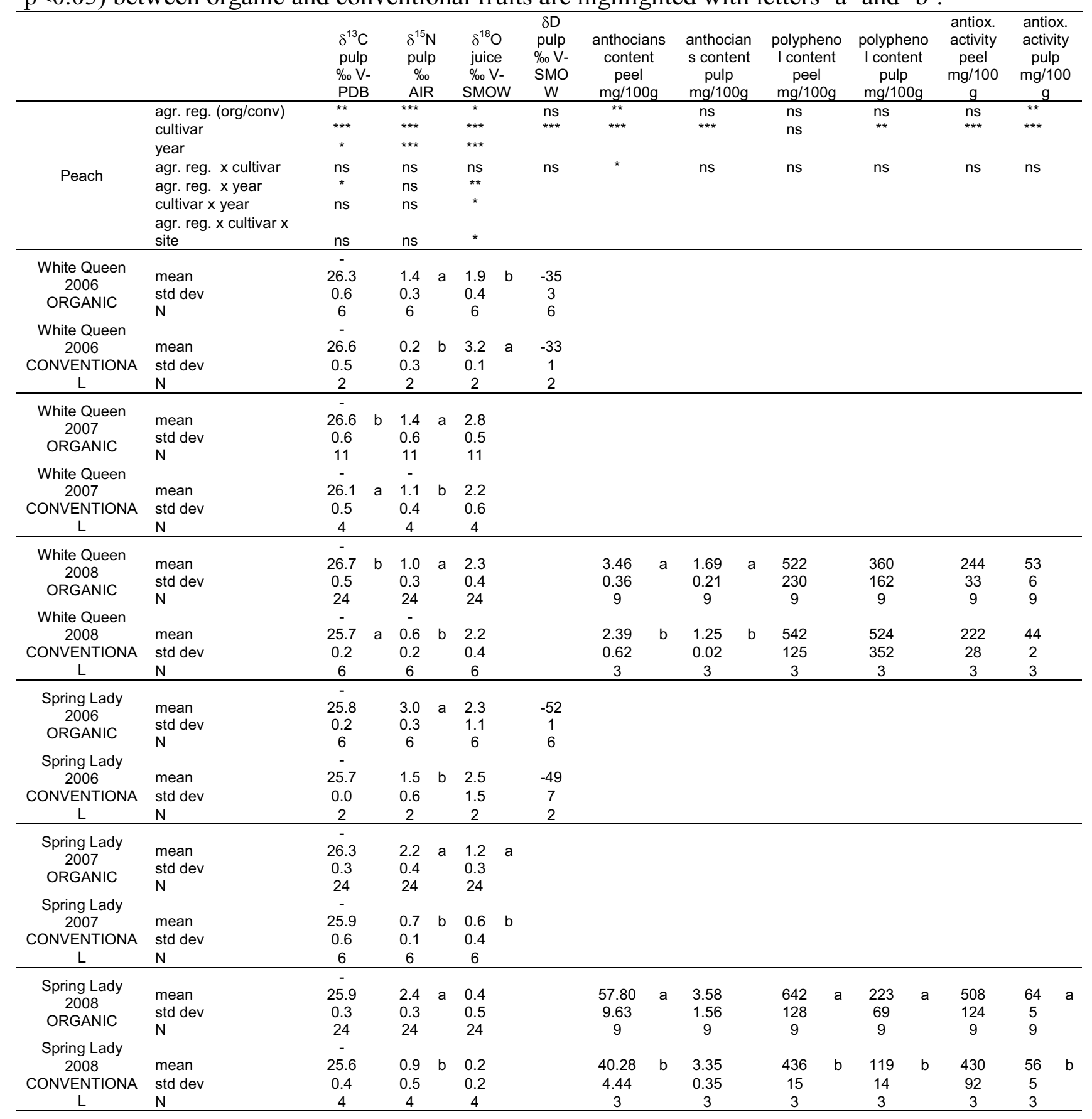


Table 4: Significance of the influence of agricultural regime (agr. reg.), site and year on isotopic and chemical characteristics and mean and standard deviation of isotopic and quality parameters for strawberry. SR: skin resistance; FF: flesh firmness; TSS: total soluble solids, TA: titratable acidity; L*: brightness; $\Delta \mathrm{E}$ : variation of colour after harvesting; $\Delta \mathrm{p}$ : Weight loss after harvesting; N: number of samples measured. ns: not significant; *: significant, $\mathrm{p}<0.05$; **: significant, $\mathrm{p}<0.01$, ***: significant, $\mathrm{p}<0.001$. Significantly different mean values (HSD Tukey's, $\mathrm{p}<0.05$ ) between organic and conventional $\frac{\text { fruits are highlighted with letters ' } a \text { ' and ' } \mathrm{b} \text { '. }}{\delta^{13} \mathrm{C} \quad \delta^{15} \mathrm{~N} \quad \delta^{18} \mathrm{O}}$

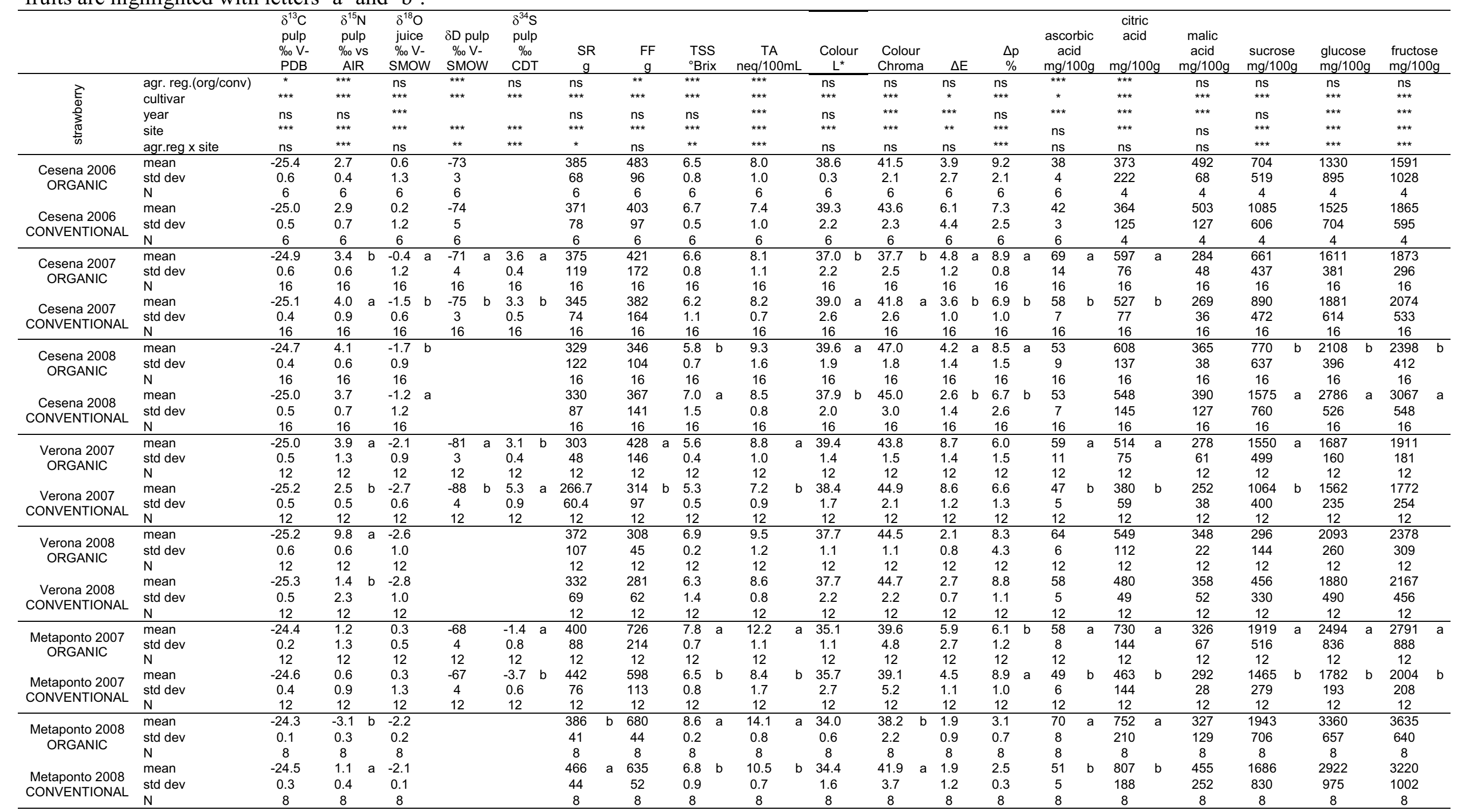

